The American Journal of Surgery 191 (2006) 230-234

Scientific papers-International

\title{
Late treatment-related complications in 214 patients with extremity soft-tissue sarcoma treated by surgery and postoperative radiation therapy
}

\author{
Lorenzo Livi, M.D. ${ }^{\mathrm{a} *}$, Riccardo Santoni, M.D. ${ }^{\mathrm{c}}$, Fabiola Paiar, M.D. ${ }^{\mathrm{a}}$, Paolo Bastiani, M.D. ${ }^{\mathrm{a}}$, \\ Giovanni Beltrami, M.D. ${ }^{\mathrm{b}}$, Patrizio Caldora, M.D. ${ }^{\mathrm{b}}$, Rodolfo Capanna, M.D. ${ }^{\mathrm{b}}$, \\ Pietro De Biase, M.D. ${ }^{b}$, Beatrice Detti, M.D. ${ }^{a}$, Simona Fondelli, M.D. ${ }^{a}$, \\ Elisa Meldolesi, M.D. ${ }^{a}$, Maurizio Pertici, M.D. ${ }^{a}$, Caterina Polli, M.D. ${ }^{a}$, \\ Gabriele Simontacchi, M.D. ${ }^{a}$, Gianpaolo Biti, M.D. ${ }^{a}$ \\ ${ }^{a}$ Department of Radiation Oncology, University of Florence, Viale Morgagni 85, 50134 Florence, Italy \\ ${ }^{\mathrm{b}}$ Department of Oncologic-Orthopaedic Surgery, CTO Hospital, Florence, Italy \\ ${ }^{\mathrm{c}}$ Department of Radiation Oncology, University of Tor-Vergata, Rome, Italy
}

Manuscript received March 7, 2005; revised manuscript September 27, 2005

\begin{abstract}
Background: We assessed the occurrence of long-bone fracture and other side effects in a group of 214 consecutive patients who underwent radical excision for soft-tissue sarcoma of the limb followed by postoperative irradiation.

Methods: Two hundred fourteen patients underwent postoperative irradiation after radical excision of soft-tissue sarcoma of the limb; 156 (73\%) received postoperative brachytherapy (BRT) plus external-beam radiation therapy (EBRT), and 58 (27\%) underwent postoperative EBRT only. All patients were followed-up for a median time of 4.5 years (range 3 months to 10 years).

Results: Seven patients developed bone fracture, which is considered severe morbidity; time between surgery and occurrence of fracture ranged between 10 and 72 months (average 31). Severe sclerosis with impairment of limb function was diagnosed in 5 and peripheral nerve damage in 3 patients. Wound complications were detected in 8 patients.

Conclusions: In our series, no statistically significant correlation between bone fracture and clinical features or "technical" parameters was found, but all of the patients who experienced bone fracture (7 of 7) were postmenopausal women $>55$ years old. () 2006 Excerpta Medica Inc. All rights reserved.
\end{abstract}

Keywords: Brachytherapy; External-beam radiation therapy; Severe morbidity; Soft-tissue sarcoma

During the last 2 decades, limb-sparing surgery and adjuvant radiotherapy have replaced amputation as the standard treatment for patients with soft-tissue sarcoma of an extremity. This approach is based on retrospective studies [1,2] as well as a prospective randomized trial showing equivalent outcomes between amputation and limb-sparing surgery plus postoperative radiation therapy [3]. Moreover, 2 prospective randomized trials, in patients randomized to receive no further treatment or postoperative radiation therapy after wide local excision of soft-tissue sarcoma, have shown better local control in those undergoing irradiation $[4,5]$.

\footnotetext{
* Corresponding author. Tel.: +1-0039-055-7947719; fax: +1-0039055-4379930.

E-mail address: 1.livi@dfc.unifi.it
}

Despite the good survival and local control rates after combined treatment with radical surgery followed by highdose radiation therapy with or without brachytherapy (BRT) [6,7], the occurrence of severe long-term side effects has not yet been fully investigated. In particular, the risk of longbone fracture is not well known.

The primary aim of this study was to report, in our experience, the frequency of bone fracture in a group of 214 consecutive patients who underwent radical softtissue sarcoma excision followed by perioperative BRT and/or external-beam irradiation (EBRT) and the frequency of other short- and long-term side effects (eg, wound complications, sclerosis with impairment of limb function, and peripheral nerve damage) considered "significant morbidities." 


\section{Material and Methods}

Between March 1990 and December 2000, 331 patients with histologically verified soft-tissue sarcomas were referred to the Radiation Therapy Department of the University of Florence, and their treatment was discussed in a soft-tissue sarcoma conference. Of the total, 214 patients with long-limb soft-tissue sarcoma underwent radical surgery followed by postoperative irradiation either by BRT + EBRT or EBRT alone; their features are listed in Table 1. Microscopic surgical margin status according to Union Internationale Contre Le Cancer (UICC) classification was as follows: in ERBT there were 146 R0 (93.5\%), 10 R1 (6.5\%), and no R2 patients. In the ERBT + BRT group, there were 52 R0 (90\%), 6 R1 (10\%), and no R2 patients. All of the patients were followed-up for a median of 4.5 years (range 3 months to 10 years). Only 6 (2.8\%) patients were lost to follow-up.

The treatment protocol was based on wide surgical resection and intraoperative implantation of catheters for peri-

Table 1

Main series characteristics

\begin{tabular}{|c|c|c|}
\hline Characteristics & $\begin{array}{l}\text { No. of Patients } \\
\text { EBRT ONLY } \\
\text { No. of patients }\end{array}$ & $\begin{array}{l}\text { EBRT + BRT } \\
\text { No. of patients }\end{array}$ \\
\hline \multicolumn{3}{|l|}{ Age in y $(\%)$} \\
\hline$>50$ & $23(39.6)$ & $86(55.1)$ \\
\hline$\leq 50$ & $35(60.4)$ & $70(44.9)$ \\
\hline \multicolumn{3}{|l|}{ Size in $\mathrm{cm}(\%)$} \\
\hline$<5$ & $29(50)$ & $76(48.7)$ \\
\hline$\geq 5$ & $29(50)$ & $80(51.3)$ \\
\hline \multicolumn{3}{|l|}{ Presentation (\%) } \\
\hline Primary & $40(69)$ & $117(75)$ \\
\hline Recurrent & $18(31)$ & $39(25)$ \\
\hline \multicolumn{3}{|l|}{ Surgical margins $(\%)$} \\
\hline R0 & $52(90)$ & $146(93.5)$ \\
\hline $\mathrm{R} 1$ & $6(10)$ & $10(6.5)$ \\
\hline $\mathrm{R} 2$ & $0(0)$ & $0(0)$ \\
\hline \multicolumn{3}{|l|}{ Histology (\%) } \\
\hline Liposarcoma & $19(32.8)$ & $50(32)$ \\
\hline MFH & $11(19)$ & $20(12.8)$ \\
\hline Synovial sarcoma & $1(1.8)$ & $14(8.9)$ \\
\hline Fibrosarcoma & $5(8.6)$ & $19(12.3)$ \\
\hline Leiomyosarcoma & $6(10.3)$ & $21(13.6)$ \\
\hline Other & $17(27.5)$ & $32(19.4)$ \\
\hline \multicolumn{3}{|l|}{ Grade $(\%)$} \\
\hline Low & 33 (56.9) & $62(39.7)$ \\
\hline High & $25(43.1)$ & $94(60.3)$ \\
\hline \multicolumn{3}{|l|}{ Site $(\%)$} \\
\hline Distal extremity & $41(70)$ & $103(66)$ \\
\hline Proximal extremity & $17(30)$ & $53(44)$ \\
\hline \multicolumn{3}{|c|}{ Postoperative chemotherapy (\%) } \\
\hline Yes & $7(12.1)$ & $14(9)$ \\
\hline No & $51(87.9)$ & $142(91)$ \\
\hline \multirow[t]{2}{*}{ Mean dose in Gy (range) } & $62.4(45-70)$ & EBRT $41(40-60)$ \\
\hline & & BRT $33.7(15-46)$ \\
\hline Median dose (Gy) & 66 & 75 \\
\hline
\end{tabular}

$\mathrm{BRT}=$ brachytherapy; EBRT = external beam radiation therapy; $\mathrm{MFH}=$ malignant fibrous histiocytoma. operative BRT. Limb-sparing wide excision with gross total removal of the tumor and a wide margin of 3 to $5 \mathrm{~cm}$ of normal tissue (proximally and distally) was obtained in all of the patients. EBRT only was delivered in 58 of 214 $(27 \%)$ and EBRT + BRT in 156 of $214(73 \%)$ patients. EBRT was planned to cover a larger volume than that treated with perioperative BRT, including all of the length of the surgical wound plus a margin of approximately $2 \mathrm{~cm}$ in both of the craniocaudal directions.

\section{Brachytherapy techniques}

Until 1998, brachytherapy was delivered using a manual after-loading technique with low-dose rate $\operatorname{Ir} 192$ wires and thereafter using remote after-loading equipment. Catheters used for irradiation were always placed intraoperatively by the radiation oncologist on the tumor bed, which was defined during the surgical procedure. Target volumes were defined by adding $2.0 \mathrm{~cm}$ to both of the craniocaudal extremities of the tumor bed and 1.5 to $2.0 \mathrm{~cm}$ laterally. After-loading catheters were implanted percutaneously approximately $1 \mathrm{~cm}$ apart and perpendicular to the surgical wound. The catheters were fixed using plastic buttons at their exit from the skin. Particular attention was paid to avoid distortions of the catheters during wound suturing.

After surgery, 2 perpendicular localization films (usually at $0^{\circ}$ and $90^{\circ}$ respectively) were obtained in the simulation room. Doses ranging between 45 and 70 Gy were delivered to the tumor bed and calculated according to the Paris system. Time elapsed between surgery and BRT ranged between 1 and 10 days (mean 5 and median 8).

\section{External-beam techniques}

EBRT followed interstitial irradiation and was delivered to a larger volume than that covered by BRT, with 2 opposed fields and high-energy photons, paying particular attention to spare as much as possible of the soft tissues opposite the compartment to be treated. The total doses delivered to the entire soft-tissue compartment, considering the EBRT + BRT group, ranged between 47 and 95 Gy (mean dose in the EBRT group was $40 \mathrm{~Gy}$, and mean dose in the BRT group was 35 Gy). Median EBRT dose only was 66 Gy, whereas median EBRT + BRT dose was 75 Gy. High doses were planned knowing that in patients with soft-tissue sarcoma, at least 60 Gy should be delivered [8-12] to achieve a reasonable local control of the disease. Delivered doses of irradiation (range and average) are listed in Table 1.

\section{Evaluation of complication rates}

Complication rates were assessed retrospectively by analysis of the clinical records and according to the National Cancer Institute's Common Toxicity Criteria [13]. Bone fracture, peripheral nerve damage ( $\geq$ grade 3 ), and wound 
complications were scored; neuromotor toxicity was assessed as well (grade 3 or 4 according to the same criteria) and defined as objective weakness with impairment of function (grade 3) or paralysis (grade 4).

\section{Results}

The 3- and 5-year local disease-free survivals were $92.6 \%( \pm 1.7 \% \mathrm{SE})$ and $91.7 \%( \pm 1.9 \% \mathrm{SE})$, respectively. Local recurrences occurred in 17 of 214 (7.9\%) patients (median time to recurrence 13 months [range 3 months to 10 years]), and their characteristics are listed in Table 2. During follow-up, morbidity was detected in 23 of the 214 reported patients $(10.7 \%)$; their characteristics and main features are listed in Table 3.

The 2- and 5-year cumulative bone fracture rates, which we considered the most relevant adverse effect detected in this group of patients, were $0.4 \%$ and $3 \%$, respectively. Seven patients developed bone fracture, and time between surgery and occurrence of the fracture ranged between 10 and 72 months (average 31). All of the fractures occurred within the high-dose-volume group treated with EBRT + BRT. Three of 7 underwent amputation of the limb, and 4 underwent minor surgery and had complete recovery and functionality. All of these patients received BRT + EBRT at total doses ranging between 66 and 75 Gy. No statistically significant correlation was demonstrated (by univariate analysis) between bone fracture occurrence and variables such as timing of treatment $(P=$ $.9)$, age at diagnosis $(P=.1)$, sex $(P=.3)$, total dose delivered $(P=.3)$ and number of sources used during interstitial preoperative irradiation $(P=.4)$. Four of these patients underwent $>1$ surgery before irradiation, and preinstall stripping had been performed during the latest sur- gical procedure. All of the 7 patients who experienced bone fracture were postmenopausal women.

Severe sclerosis with impairment of limb function was diagnosed in 5 and peripheral nerve damage in 3 patients: lunar nerve palsy and hand motion incapacity in 1, tibia nerve palsy and foot motion in 1 , and chronic tight pain because of femoral nerve damage in 1 patient. In all of these patients, time between surgery and occurrence of nerve damage ranged between 12 and 36 months (average 27). All of the patients had received BRT followed-up by EBRT at total doses $>70$ Gy.

Wound complications developed in 8 patients. Three had severe skin ulceration. Two of them underwent amputation of the limb ( 1 of them had received EBRT only delivering 66 Gy to the target and the other had BRT + EBRT at a total dose of $79 \mathrm{~Gy}$ ); the third, treated with EBRT only, received topical care. Wound separation occurred in 3 patients during EBRT, and the treatment was interrupted and never concluded. All of them had received BRT before EBRT at doses ranging from 35 to $40 \mathrm{~Gy}$.

\section{Comments}

Different approaches-including postoperative EBRT, BRT, and intraoperative radiation therapy - have been proposed and used for the adjuvant management of soft-tissue sarcomas. After surgery and definitive pathology of the operative specimen, it is possible to plan accurate irradiation of the target, and BRT may be used as the exclusive perioperative treatment or as a boost to EBRT to treat residual disease on the tumor bed. The American Brachytherapy Society's recommendations for BRT of soft-tissue sarcomas [14] described the advantages of BRT in terms of shorter

Table 2

Features of 17 patients with local recurrence

\begin{tabular}{|c|c|c|c|c|c|c|c|}
\hline Patient no. & Age (y) & Sex & Histology & Grade & Size $(\mathrm{cm})$ & Dose (Gy) & Technique \\
\hline 2 & 55 & M & $\mathrm{MFH}$ & Low & $\leq 5$ & 60 & EBRT \\
\hline 4 & 61 & M & MFH & High & $>5$ & 75 & $\mathrm{EBRT}+\mathrm{BRT}$ \\
\hline 5 & 62 & $\mathrm{~F}$ & LIPO & High & $<5$ & 79 & $\mathrm{EBRT}+\mathrm{BRT}$ \\
\hline 6 & 70 & M & LIPO & High & $<5$ & 79 & $\mathrm{EBRT}+\mathrm{BRT}$ \\
\hline 9 & 54 & $\mathrm{~F}$ & MFH & High & $>5$ & 75 & $\mathrm{EBRT}+\mathrm{BRT}$ \\
\hline 10 & 49 & $\mathrm{~F}$ & LEIO & Low & $>5$ & 75 & $\mathrm{EBRT}+\mathrm{BRT}$ \\
\hline 11 & 47 & M & LEIO & High & $>5$ & 75 & $\mathrm{EBRT}+\mathrm{BRT}$ \\
\hline 12 & 46 & $\mathrm{~F}$ & $\mathrm{O}$ & High & $<5$ & 75 & $\mathrm{EBRT}+\mathrm{BRT}$ \\
\hline 13 & 55 & M & FIBRO & Low & $>5$ & 75 & $\mathrm{EBRT}+\mathrm{BRT}$ \\
\hline 14 & 44 & M & $\mathrm{MFH}$ & High & $>5$ & 70 & $\mathrm{EBRT}+\mathrm{BRT}$ \\
\hline
\end{tabular}

$\mathrm{BRT}=$ brachytherapy; EBRT $=$ external beam radiation therapy; $\mathrm{O}=$ other histology; $\mathrm{MFH}=$ malignant fibrous histocytoma; LIPO $=$ liposarcoma; FIBRO = fibrosarcoma; LEIO = leiomyosarcoma; SYNO = synovial sarcoma. 
Table 3

Clinicopathologic and treatment features of patients with and without morbidity

\begin{tabular}{|c|c|c|}
\hline Features & $\begin{array}{l}\text { Patients with } \\
\text { morbidity }\end{array}$ & $\begin{array}{l}\text { Patients without } \\
\text { morbidity }\end{array}$ \\
\hline Bone fractures & $7 / 23$ & $207 / 214$ \\
\hline $\mathrm{BRT}+\mathrm{EBRT}$ & 7 & 150 \\
\hline EBRT only & - & 57 \\
\hline \multicolumn{3}{|l|}{ Dose (Gy) } \\
\hline$>66$ & 7 & 141 \\
\hline$\leq 66$ & - & 66 \\
\hline \multicolumn{3}{|l|}{ Sex } \\
\hline Female & 7 & 87 \\
\hline Male & - & 120 \\
\hline \multicolumn{3}{|l|}{ Age (y) } \\
\hline$\geq 50$ & 7 & 100 \\
\hline$<50$ & - & 107 \\
\hline Fibrosis & $5 / 23$ & $209 / 214$ \\
\hline $\mathrm{BRT}+\mathrm{EBRT}$ & 5 & 151 \\
\hline EBRT only & - & 58 \\
\hline \multicolumn{3}{|l|}{ Dose (Gy) } \\
\hline$>66$ & 5 & 142 \\
\hline$\leq 66$ & - & 67 \\
\hline \multicolumn{3}{|l|}{ Sex } \\
\hline Female & 2 & 91 \\
\hline Male & 3 & 118 \\
\hline \multicolumn{3}{|l|}{ Age $(y)$} \\
\hline$\geq 50$ & 3 & 104 \\
\hline$<50$ & 2 & 105 \\
\hline Peripheral nerve damage & $3 / 23$ & $211 / 214$ \\
\hline $\mathrm{BRT}+\mathrm{EBRT}$ & 3 & 153 \\
\hline EBRT only & - & 58 \\
\hline \multicolumn{3}{|l|}{ Dose (Gy) } \\
\hline$>66$ & 3 & 143 \\
\hline$\leq 66$ & - & 68 \\
\hline \multicolumn{3}{|l|}{ Sex } \\
\hline Female & 2 & 91 \\
\hline Male & 1 & 120 \\
\hline \multicolumn{3}{|l|}{ Age (y) } \\
\hline$\geq 50$ & 2 & 105 \\
\hline$<50$ & 1 & 106 \\
\hline Wound complication & $8 / 23$ & $206 / 214$ \\
\hline $\mathrm{BRT}+\mathrm{EBRT}$ & 6 & 151 \\
\hline EBRT only & 2 & 55 \\
\hline \multicolumn{3}{|l|}{ Dose (Gy) } \\
\hline$>66$ & 5 & 143 \\
\hline$\leq 66$ & 3 & 63 \\
\hline \multicolumn{3}{|l|}{ Sex } \\
\hline Female & 5 & 89 \\
\hline Male & 3 & 117 \\
\hline \multicolumn{3}{|l|}{ Age (y) } \\
\hline$\geq 50$ & 5 & 102 \\
\hline$<50$ & 3 & 104 \\
\hline
\end{tabular}

$\mathrm{BRT}=$ brachytherapy; EBRT $=$ external beam radiation therapy.

overall treatment time, decreased patient discomfort, decreased financial cost of treatment, safer delivery of higher doses to the tumor bed, and normal tissue sparing. Moreover, the American Brachytherapy Society pointed out that complications after BRT for soft-tissue sarcomas are to be considered multifactorial because of patient heterogeneity, disease extent, and anatomic site involved. In the same report, recommendations that may contribute to decreased acute complications are listed, but little is suggested concerning the occurrence of late side effects and possible interventions to minimize such morbidity.

The occurrence of bone fracture after adjuvant postoperative irradiation for soft-tissue sarcomas of the limbs, as well as the occurrence of other late side effects such as fibrosis with impairment of function and peripheral nerve damage, has not been clearly established in the literature. Most of the reports and available data focus on the occurrence of wound complications as an acute side effect of irradiation. Wound complications in 54 patients treated between July 1982 to March 1985 were reported by Arbeit et al [15], who found a complication rate significantly higher in the BRT arm (48\%) compared with the non-BRT $\operatorname{arm}(16 \%)(P=.01)$. In contrast, Ormsby et al [16] reported no difference in the rate of significant wound complications between the BRT arm (14\%) and the non-BRT arm (10\%). These data compare well with our experience (8 of 227 patients had $3.5 \%$ of wound complications) despite the fact that heterogeneity of the treatment and the patients may not allow direct comparison of the results.

Concerning bone fracture occurrence, Stinson et al [17] reported 145 patients with soft-tissue sarcomas who underwent limb-sparing surgery and postoperative radiation with or without chemotherapy and found a $6 \%$ fracture rate. Brant et al reported a $7.6 \%$ rate of pathologic fracture in patients treated with preoperative irradiation [18]. Alektiar et al $[19,20]$ reported a $4.6 \%$ rate of bone fracture in the BRT arm compared with none in the non-BRT arm $(P=.2)$. Lin et al [21] evaluated 205 patients with soft-tissue sarcomas of the thigh and reported (by univariate analysis) 2 factors associated with increased bone fracture represented: periosteal stripping (29\% vs. $0 \% P=.0001)$ and use of EBRT $(21 \%$ vs. $5 \% P=.04)$.

In our series, 7 patients experienced bone fracture during follow-up after surgery and postoperative irradiation combining BRT + EBRT. Despite the fact that analysis of these data did not show any statistically significant evidence correlating bone fracture occurrence with the main features of the tumor or of the patients, we emphasize out the following observations:

1. Age and sex: Twelve of 15 patients with late side effects (bone fracture, fibrosis, or nerve damage) were $>50$ years old at the time of treatment, and 11 of these women were postmenopausal. All of the patients who experienced bone fracture (7 of 7) were postmenopausal women $>55$ years old. Menopausal status might probably be regarded as an important cofactor in the occurrence of bone fracture [22].

2. Delivered dose: All of the patients with late side effects (bone fracture, severe fibrosis, or nerve damage) received a total dose $>66$ Gy with a combination of EBRT + BRT.

3. Primary or recurrent tumour and number of surgical procedures: To our knowledge, only 1 study in the 
literature [23] has reported a case of osteonecrosis out of 26 patients treated with BRT for recurrent sarcoma after local excision; in our experience, 3 patients underwent $>1$ surgical procedure before receiving radiation therapy. Despite that this too is not a significant predictor of late damage, it should probably be considered when planning perioperative and postoperative irradiation.

In conclusion, BRT used alone or in combination with EBRT may contribute to local control in patients undergoing surgery for soft-tissue sarcomas. The occurrence of severe late side effects, in particular the occurrence of bone fracture, has not been established, but its occurrence must be considered before planning and delivering treatment. In our series, no statistically significant correlation between bone fracture and clinical features or "technical" parameters was found. Nevertheless, menopausal status should be regarded as a possible cofactor in the occurrence of bone fracture in women $>55$ years old.

\section{References}

[1] Suit H, Russell W, Martin R. Management of patients with sarcoma of soft tissue in an extremity. Cancer 1973;31:1237-45.

[2] Lindberg R, Martin R, Romsdahl M, et al. Conservative surgery and postoperative radiotherapy in 300 adults with soft-tissue sarcoma. Cancer 1981;47:2391-7.

[3] Rosenberg SA, Tepper J, Glatstein E, et al. The treatment of softtissue sarcomas of the extremities: prospective randomized evaluations of (1) limb-sparing surgery plus radiation therapy compared with amputation and (2) the role of adjuvant chemotherapy. Ann Surg 1982;196:305-15.

[4] Pisters PW, Harrison LB, Leung DH, et al. Long-term results of a prospective randomized trial of adjuvant brachytherapy in soft tissue sarcoma. J Clin Oncol 1996;14:859-68.

[5] Yang J, Chang A, Baker A, et al. Randomized prospective study of the benefit of adjuvant radiation therapy in the treatment of tissue sarcomas of the extremity. J Clin Oncol 1998;16:197-203.

[6] Harrison LB, Franzese F, Gaynor JJ, et al. Long-term results of a prospective randomized trial of adjuvant brachytherapy in the management of completely resected soft tissue sarcomas of the extremity and superficial trunk. Int J Radiat Oncol Biol Phys 1993;27:259-65.

[7] Suit HD, Mankin HJ, Wood WC, et al. Treatment of the patient with stage M0 soft tissue sarcoma. J Clin Oncol 19886:854-62.

[8] Zagars GK, Ballo MT. Significance of dose in postoperative radiotherapy for soft tissue sarcoma. Int J Radiat Oncol Biol Phys 2003; $56: 473-81$.
[9] Fein DA, Lee WR, Lanciano RM, et al. Management of extremity soft tissue sarcomas with limb-sparing surgery and postoperative irradiation: do total dose, overall treatment time, and the surgeryradiotherapy interval impact on local control? Int J Radiat Oncol Biol Phys 1995;32:969-76.

[10] Mundt AJ, Awan A, Sibley GS, et al. Conservative surgery and adjuvant radiation therapy in the management of adult soft tissue sarcoma of the extremities: clinical and radiobiological results. Int $\mathbf{J}$ Radiat Oncol Biol Phys 1995;32:977-85.

[11] Wolfson AH, Benedetto PW, Mnaymneh W, et al. Does a radiation dose-response relation exist concerning survival of patients who have soft-tissue sarcomas of the extremities? Radiation dose-response relation for soft-tissue sarcomas. Am J Clin Oncol 1998;21:270-4.

[12] Andrews SF, Anderson PR, Eisenberg BL, et al. Soft tissue sarcomas treated with postoperative external beam radiotherapy with and without low-dose-rate brachytherapy. Int J Radiat Oncol Biol Phys 2004; 59:475-80.

[13] National Cancer Institute's Common Toxicity Criteria Manual, Version 2.0. June 1, 1999:33.

[14] Nag S, Shasha D, Janjan N, et al. The American Brachytherapy Society recommendations for brachytherapy of soft tissue sarcomas. Int J Radiat Oncol Biol Phys 2001;49:1033-43.

[15] Arbeit JM, Hilaris BS, Brennan MF. Wound complications in the multimodality treatment of extremity and superficial truncal sarcomas. J Clin Oncol 1987;5:480-8.

[16] Ormsby MV, Hilaris BS, Nori D, et al. Wound complications of adjuvant radiation therapy in patients with soft-tissue sarcomas. Ann Surg 1989;210:93-9.

[17] Stinson SF, DeLaney TF, Greenberg J, et al. Acute and long-term effects on limb function of combined modality limb sparing therapy for extremity soft tissue sarcoma. Int J Radiat Oncol Biol Phys 1991;21:1493-9.

[18] Brant TA, Parsons JT, Marcus RB, et al. Preoperative irradiation for soft tissue sarcomas of the trunk and extremities in adults. Int J Radiat Oncol Biol Phys 1990;19:899-906.

[19] Alektiar KM, Zelefsky MJ, Brennan MF. Morbidity of adjuvant brachytherapy in soft tissue sarcoma of the extremity and superficial trunk. Int J Radiat Oncol Biol Phys 2000;47:1273-9.

[20] Alektiar K, Leung D, Brennann M, et al. The effect of combined external beam radiotherapy and brachytherapy on local control and wound complications in patients with high grade soft tissue sarcomas of the extremity with positive microscopic margin. Int J Radiat Oncol Biol Phys 1996;36:231-4.

[21] Lin PP, Schupak KD, Boland PJ, et al. Pathologic femoral fracture after periosteal excision and radiation for the treatment of soft tissue sarcoma. Cancer 1998;82:2356-65.

[22] Kanterewicz E, Yanez A, Perez-Pons A, et al. Association between Colles' fracture and low bone mass: age-based differences in postmenopausal women. Osteoporosis Int 2002;13:824-8.

[23] Pearlstone DB, Janjan NA, Feig BW, et al. Re-resection with brachytherapy for locally recurrent soft tissue sarcoma arising in a previously radiated field. Cancer J Sci Am 1999;5:26-33. 